\title{
Gene expression biomarkers of response to citalopram treatment in major depressive disorder
}

\author{
F Mamdani ${ }^{1}$, MT Berlim ${ }^{1}$, M-M Beaulieu ${ }^{1}$, A Labbe $^{3,4}$, C Merette $^{2}$ and G Turecki ${ }^{1}$
}

There is significant variability in antidepressant treatment outcome, with $\sim 30-40 \%$ of patients with major depressive disorder (MDD) not presenting with adequate response even following several trials. To identify potential biomarkers of response, we investigated peripheral gene expression patterns of response to antidepressant treatment in MDD. We did this using Affymetrix HG-U133 Plus2 microarrays in blood samples, from untreated individuals with MDD $(N=63)$ ascertained at a community outpatient clinic, pre and post 8-week treatment with citalopram, and used a regression model to assess the impact of gene expression differences on antidepressant response. We carried out technical validation of significant probesets by quantitative reverse transcriptase PCR and conducted central nervous system follow-up of the most significant result in post-mortem brain samples from 15 subjects who died during a current MDD episode and 11 sudden-death controls. $A$ total of 32 probesets were differentially expressed according to response to citalopram treatment following false discovery rate correction. Interferon regulatory factor 7 (IRF7) was the most significant differentially expressed gene and its expression was upregulated by citalopram treatment in individuals who responded to treatment. We found these results to be concordant with our observation of decreased expression of IRF7 in the prefrontal cortex of MDDs with negative toxicological evidence for antidepressant treatment at the time of death. These findings point to IRF7 as a gene of interest in studies investigating genomic factors associated with antidepressant response.

Translational Psychiatry (2011) 1, e13; doi:10.1038/tp.2011.12; published online 21 June 2011

\section{Introduction}

Major depressive disorder (MDD) is a debilitating and chronic condition that affects between 5 and $10 \%$ of the general population. ${ }^{1}$ The treatment of MDD includes a variety of biopsychosocial approaches, but in frontline medical practice, it is primarily based on pharmacological interventions, commonly with an initial prescription of a serotonin selective reuptake inhibitor antidepressant. ${ }^{2-5}$ Although antidepressants are generally effective, and in spite of a growing number of different types and classes, there is significant variability in antidepressant treatment outcome. Almost $60 \%$ of patients do not recover following a single antidepressant trial, ${ }^{6}$ and 30 to $40 \%$ of patients do not present with an adequate response following several trials. ${ }^{2,4,5}$ The failure to respond has important individual, economic and social consequences for both patients and their families.

Although it would be ideal to better target available treatments to individual patients, we know little about predictors of response. Among factors associated with response to antidepressant treatment in MDD, depression severity, comorbid anxiety disorders, longer duration and frequency of previous episodes and an older age of onset have all been identified as predictors of poor response. ${ }^{7}$ However, given low sensitivity and specificity, none of these factors are useful when planning treatment options for MDD patients. ${ }^{7}$ Response to pharmacological treatment has also been demonstrated to segregate in families. Only a handful of studies, however, have investigated familial patterns of response to antidepressants, ${ }^{8-10}$ and subsequent studies have investigated the association of genetic variants with treatment response. As the downstream effects of different predictors of antidepressant response-be they genetic and/ or environmental-should ultimately be mediated by changes in gene function, investigating predictors and underlying biological factors associated with response by means of gene expression studies may provide valuable information and help identify biomarkers of antidepressant response. This approach has been favorably used in the investigation of response to treatment for several medical conditions, such as breast cancer, ${ }^{11-13}$ colon cancer ${ }^{14}$ and cardiovascular disease. ${ }^{15-17}$

In the context of neuropsychiatric disorders, peripheral blood gene expression studies of drug response have value beyond a proxy model of central nervous system (CNS) phenomena, given that both peripheral and central processes are involved in the individual response to treatment. Surprisingly, to date, most studies investigating gene expression changes to antidepressant treatment have been performed in patients with Alzheimer's disease, ${ }^{18-20}$ whereas most studies

\footnotetext{
${ }^{1}$ McGill Group for Suicide Studies and Depressive Disorders Program, Douglas Mental Health University Institute, Montréal, Quebec, Canada; ${ }^{2}$ Centre de Recherche Université Laval Robert-Giffard, Quebec City, Quebec, Canada; ${ }^{3}$ Department of Psychiatry, McGill University, Montréal, Quebec, Canada and ${ }^{4}$ Department of Epidemiology, Biostatistics and Occupational Health, McGill University, Montréal, Quebec, Canada

Correspondence: Dr G Turecki, McGill Group for Suicide Studies, Douglas Mental Health University Institute, 6875 LaSalle Boulevard, Verdun, Montréal, Quebec H4H 1R3, Canada.

E-mail: Gustavo.turecki@mcgill.ca

Keywords: antidepressants; biomarkers; peripheral gene expression; pharmacogenomics; post-mortem brain gene expression

Received 10 May 2011; accepted 10 May 2011
} 
of antidepressant response in depression have been carried out in rodent models. There is limited, although promising, work probing gene expression changes associated with antidepressant response in patients with MDD. ${ }^{21-23}$ Here, we report on a study assessing changes in genome-wide expression as a function of 8-week citalopram treatment response in a sample of patients with current MDD who were untreated at the study onset. To our knowledge, this is the first genome-wide expression study investigating patterns of response to antidepressant treatment in MDD patients.

\section{Materials and methods}

MDD sample. Our subjects were untreated males and females $(N=63)$ with a diagnosis of MDD without psychotic features, according to the SCID-1 (Structured Clinical Interview for Diagnostic and Statistical Manual of Mental Disorders-fourth edition (DSM-IV) Axis I Disorders) ascertained at a community outpatient clinic at the Douglas Mental Health University Institute (see Supplementary Table 1 for clinical details). Subjects were excluded from the study if they had comorbidity with other major psychiatric disorders, including a previous manic or hypomanic episode (diagnosis of bipolar disorder) or a diagnosis of schizophrenia. However, subjects were not excluded if they presented with anxious traits, as anxiety is highly comorbid with MDD. They were also excluded if they presented comorbidity with substance disorders or if they had positive tests for illicit drugs, both pre- and post-citalopram treatment. Subjects could not have had previously used citalopram and could not have been treated for the current episode of major depression if they had a recurrent form of MDD $(46.8 \%$ recurrent MDD; Figure 1).

Citalopram treatment. Patients were treated with citalopram for a total of 8 weeks, starting with an initial dose of $10 \mathrm{mg}$ per day, which was subsequently titrated up to a maximum of $60 \mathrm{mg}$ per day. Assessments of depression severity were carried out three times during the trial (pretreatment, 1 month after and post-treatment commencement) using the 21-item Hamilton Rating Scale for Depression (HAMD-21).

Blood samples and RNA processing. Blood samples were collected in six PAXgene blood RNA tubes (PreAnalytix, Hombrechtikon, Switzerland) and two EDTA vacutainer tubes
(BD, Mississauga, Ontario, Canada) from cases before the start of the trial and again at trial completion. PAXgene tubes were frozen using a sequential freezing process. This involved storing tubes at room temperature for $3 \mathrm{~h}$, transferring to $4{ }^{\circ} \mathrm{C}$ overnight, $-20^{\circ} \mathrm{C}$ for $6-8 \mathrm{~h}$ and then finally to $-80^{\circ} \mathrm{C}$. Four tubes were used for RNA extraction and microarray processing and the remaining two tubes were kept at $-80^{\circ} \mathrm{C}$ for subsequent RNA extraction and microarray validation studies. The EDTA tubes were used to obtain plasma for citalopram concentration measures. All subjects included in the study provided informed consent and the project was approved by the internal review board for the Douglas Mental Health University Institute.

The RNA used in this study had a minimum A260/A280 ratio of >1.9. Integrity and possible degradation of the RNA samples was determined using a 2100 Bioanalyzer (Agilent Technologies, Palo Alto, CA, USA) and samples had an average RNA integrity number of 8.4 and a $28 \mathrm{~S} / 18 \mathrm{~S}$ ratio of $>1.6$.

High-performance liquid chromatography. High-performance liquid chromatography analysis was carried out to determine subject compliance at the end of the trial. Citalopram concentrations were determined from plasma removed from week 8 blood tubes following centrifugation. Plasma samples were transferred to cryogenic tubes for storage at $-80^{\circ} \mathrm{C}$ until time for use.

For drug extraction, $1 \mathrm{ml}$ of plasma was first spiked with $150 \mathrm{ng}$ desipramine, which acted as an internal standard, and then basified with $100 \mu \mathrm{l} \mathrm{NaOH}$. To this, $10 \mathrm{ml}$ of $1 \%$ butanol:isoamyl alcohol was added to bring the drug into the aqueous phase. The drug was then back-extracted using $200 \mu \mathrm{HCl}$, and subsequently $50 \mu \mathrm{l}$ was injected into the highperformance liquid chromatography machine. The samples were run through a reverse-phase $\mathrm{C}-18$ column and peaks were detected with an ultraviolet detector. Citalopram concentration measures were derived using a standard curve constructed from plasma spiked with known concentrations of citalopram and processed as mentioned above. To take into account intraday variability, new standard curves were made before each high-performance liquid chromatography run.

Microarrays. We used the Affymetrix GeneChip Human Genome U133 Plus 2.0 array (Affymetrix, Santa Clara, CA, USA), consisting of 54000 probesets, allowing for the analysis of 47000 transcripts, representative of 38500

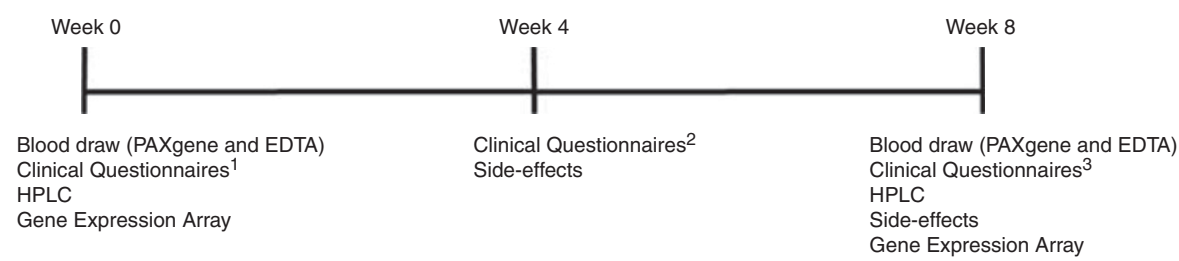

Figure 1 Timeline and steps taken within the 8-week citalopram trial. ${ }^{1}$ SCID-I; SCID-II; sociodemographic questionnaire; HAMD-21 and Hamilton Anxiety questionnaire. ${ }^{2}$ HAMD-21 and Hamilton Anxiety questionnaire. ${ }^{3}$ HAMD-21 and Hamilton Anxiety questionnaire. Abbreviations: HAMD-21, 21-item Hamilton Rating Scale for Depression; HPLC, high-performance liquid chromatography; SCID-I, Structured Clinical Interview for Diagnostic and Statistical Manual of Mental Disorders-fourth edition (DSM-IV) Axis I Disorders; SCID-II, Structured Clinical Interview for DSM-IV Axis II Personality Disorders. 
human genes. Sample preparation and processing hybridization to the array and normalization were performed as suggested by the manufacturer and described in the Affymetrix GeneChip Expression Analysis Manual (Affymetrix). The GeneChip IVT Express and the GeneChip Hybridization, Wash and Stain kits from Affymetrix were used for first and second complementary DNA synthesis, IVT/labeling and purification of RNA, fragmentation and purification. GeneChip analysis was performed as described below.

Data analysis. Normalization of gene expression arrays was executed using Robust Multi-Array as implemented in Partek Genomics Suite (Partek, St Louis, MO, USA; Version 6.3 (03.10.08)), with initial probeset filtering based on Microarray Suite 5 (MAS5) present/absent calls, whereby only those probesets present in at least $75 \%$ of the total sample were retained for further analysis. This filtering procedure is based on the methods described by McClintick and Edenberg ${ }^{24}$ whereby the use of present-call filtering functions in minimizing the impact of large differential signals explained by a small proportion of the sample. Following this procedure, the number of probesets was reduced to 19277 . We also removed probesets associated with the $Y$ chromosome to minimize the likelihood of false positive results arising from the inclusion of probesets from this chromosome. Several indicators of RNA quality were used to prefilter samples before analysis; these included $\beta$-actin $5^{\prime} / 3^{\prime}$ ratio $(\geqslant 0.3)$, glyceraldehyde 3 -phosphate dehydrogenase (GAPDH) $5^{\prime} / 3^{\prime}$ ratio $(\geqslant 0.5)$ and RawQ. Outlier detection for arrays was also carried out using principal component analysis.

Following initial filtering, the remaining analyses were carried out using the statistical software R (www.r-project.org). For the identification of the number of probesets to be used in our analyses to identify a set of differentially expressed genes according to response to citalopram treatment, we used a two-step statistical approach. First, we preselected a set of 1160 genes showing the highest fold change in $\log _{2}$ expression between pre- and post-treatment. In our sample, this corresponded to a fold change $\geqslant 1.08$ or, alternatively, $\leqslant 0.92$. Subsequently, a regression model was carried out for each gene using the difference between pre- and postHAMD-21 scores as the dependent variable and the difference in $\log _{2}$ expression as the independent variable. We accounted for the multiplicity of tests by adjusting the $P$-values such that the false discovery rate (FDR) was $<10 \%$.

Gene expression validation. The GenomeLab GeXP Genetic Analysis System (Beckman Coulter, Mississauga, Ontario, Canada) was used to validate significant gene expression findings. This was carried out through Genome Quebec at the RNomics Laboratory at the University of Sherbrooke (Sherbrooke, Quebec, Canada). The GeXP system enabled the multiplexing of 30 genes within a single sample well through the use of both gene-specific and universal primers for amplification of complementary DNA fragments of varying length. Using capillary electrophoresis, at the end of the PCR, fragments migrate by size and thus separate into gene-specific bands, which can be visualized as peaks in a chromatogram. The area under the curve is equivalent to the concentration of mRNA in the original sample. The concentration measures are scaled to a control RNA sample, which was included on each plate and then normalized to GAPDH. The sample used for this consisted of pre- and post-RNA samples for all subjects included in the analyses and a control RNA sample from peripheral blood.

Follow-up gene expression studies in the prefrontal cortex. A TaqMan gene expression assay for interferon regulatory factor 7 (IRF7) was used to investigate the expression of this gene in an all-male sample of 15 subjects who died during a depressive episode (average age $=36.8 \pm 11.2$ years) and a group of 11 sudden-death, psychiatrically normal controls (average age $=34.3 \pm 11.5$ years) in the prefrontal cortex. The groups were similar in age $(P=0.42)$, brain $\mathrm{pH}(P=0.481)$ or post-mortem interval $(P=0.854)$. Toxicological investigation of post-mortem tissue showed no evidence of antidepressants or other psychotropic treatments. RNA was extracted from brain tissue using the RNeasy Lipid Tissue Kit from Qiagen (Toronto, Ontario, Canada). RNA concentration was assessed using a Nanodrop (Thermo Scientific, Wilmington, DE, USA) and RNA quality using the 2100 Bioanalyzer (Agilent Technologies, Santa Clara, CA, USA), and brain samples had an average RNA integrity number of 7.2. Complementary DNA was produced using Moloney murine leukemia virus reverse-transcriptase and Oligo-dT primers and subsequently diluted to a concentration of $2.5 \mathrm{ng} \mathrm{\mu l}^{-1}$ for use in quantitative reverse transcriptase-PCR. Quantitative reverse transcriptase- was performed in 384-well plates on the 7900HT Real-Time PCR system from Applied Biosystems (Carlsbad, CA, USA) under fast conditions using PerfeCTa qPCR Fastmix (Quanta Biosciences, Gaithersburg, MD, USA). Target and endogenous control ( $\beta$-actin) were run in the same well and plates were analyzed using the $\Delta$ Ct method in $R Q$ Manager (Applied Biosystems) with the calibrator being a sample with low variability between replicates.

\section{Results}

A total of 63 subjects with MDD were treated with citalopram for 8 weeks and their gene expression profiles were obtained pre- and post-treatment. Demographic and baseline clinical variables had no significant effect on treatment outcome (Supplementary Table 2). We observed no instances of suicidal behavior or significant increase in ideation during the trial, necessitating trial discontinuation. As well, past suicidal behavior had no effect on the results observed in the citalopram sample. Side effects were measured after 4 and 8 weeks of treatment, and there were no significant differences between responders and nonresponders in sideeffect profiles at week $4(P$-value $=0.98)$ or at week 8 $(P$-value $=0.08)$. All subjects had detectable levels of serum citalopram at the end of 8 weeks, and we observed a significant correlation between citalopram dose and plasma concentration $(r=0.392, P$-value $=0.002)$.

Differential gene expression according to treatment irrespective of treatment response. At the outset, probesets were filtered based on their presence in $75 \%$ of 
the total sample, resulting in a reduction of the total number of probesets to 19277 . The first step in our analyses was to select a subset of probesets showing change in expression according to treatment irrespective of response. Three criteria were used for this purpose: (1) significance, (2) fold change and (3) effect size. The lists of probesets pertaining to each criterion are summarized in Supplementary Tables 3-5. The Venn diagram (Supplementary Figure 1) illustrates the number of probesets unique and common to each of the aforementioned criteria. The 417 common probesets were then used in the analysis of treatment response, as outlined below.

\section{Gene expression changes associated with response to} antidepressant treatment. For the assessment of response, we did not utilize the more traditional procedure of dichotomization of subjects into responder and nonresponder groups based on a HAMD cutoff, but opted instead to analyze response quantitatively. This is because of HAMD scores being continuous measures and the fact that depressive/ response states are not necessarily categorical following 8 weeks of treatment. Furthermore, from a statistical point of view, dichotomization of continuous variables is not recommended as it can result in an unnecessary loss of information, as well as lead to reduced statistical power and an increased probability of type II error. ${ }^{25}$

In order to determine gene expression changes associated with treatment response, we conducted regression analyses using the log fold change of the 417 differentially expressed probesets, which are differentially expressed according to treatment, to predict the change in HAMD scores between pre and post-treatment. We found that changes in the expression of 69 probesets significantly predicted the change in HAMD scores following treatment $(P$-value $<0.05)$. Of these, 32 probesets remained statistically significant after FDR correction (FDR $\leqslant 0.10$; Table 1 ). Using DAVID $^{26}$ to probe overrepresented ontologies, these probesets were found to code for genes involved in immune response, transcription factors, apoptosis and other cellular processes (Table 2). Among the 32 probesets, probeset 208436_s_at, which maps to the gene coding for IRF7, a transcription factor regulating the cytokine interferon- $\alpha$, was the only one that was significantly associated with the change in depression severity using an FDR of 0.05 .

Technical validation of microarray findings. The validation results are shown in Table 3. Expression values in the validation assays were consistent and in the same direction with those observed in the array; however, only eight of these genes displayed significant correlations. IRF7 expression values observed using these techniques were similar to those seen using the microarrays. To exclude the possibility that the differences observed in IRF7 were because of inflammatory processes associated with possible infections, we investigated whether they were associated with changes in white cell counts. However, no significant differences were observed between pre- and posttreatment measures $(P=0.12)$.

Expression of IRF7 in prefrontal cortex. To gain insight into the possible CNS validity of our peripheral results, we investigated IRF7 expression in prefrontal cortex, a brain region thought to play an important role in the neurobiology of major depression. ${ }^{27}$ To this end, we studied the levels of IRF7 by means of quantitative reverse transcriptase-PCR using a TaqMan assay in 15 subjects who died in the context of an episode of MDD and 11 sudden-death controls with comparable age, post-mortem interval, RNA integrity number and $\mathrm{pH}$, and no current or lifetime history of MDD. We found that IRF7 was significantly downregulated in MDD subjects when compared with controls (fold change $=-1.74$, $P$-value $=0.01)$.

\section{Discussion}

A large proportion of patients taking antidepressants display unfavorable or minimal response and, as a consequence, they typically are exposed to multiple antidepressant trials and endure a protracted illness course. The potential individual and societal advantages resulting from the effective identification of biomarkers of antidepressant response are numerous and ranging from economic benefits to reduced medical and social burden. In this study we carried out an analysis of peripheral gene expression with the aim of determining potential biomarkers for response to citalopram. We have identified a set of 32 probesets whose differential expression is significantly associated with the change observed in depression severity following treatment. As well, we have found additional evidence for the role of immune dysregulation in both the periphery and the brain.

IRF7 is part of a nine-member transcription factor family responsible for the transcriptional regulation of interferonmediated signaling pathways. ${ }^{28}$ IRF7 has been shown to complex with IRF1, IRF3 and histone transacetylases to regulate transcription of the proinflammatory cytokine, interferon- $\alpha$. In our study, we observed an upregulation of IRF7 following treatment with citalopram. IRF7 upregulation could be the result of citalopram stimulating fluctuations in interferon levels, ${ }^{29}$ or through IRF7 promoter methylation. ${ }^{30}$ Initiation of the inflammatory immune response gives rise to changes in neuromodulatory effects mimicking the outcomes elicited by stressful life events. ${ }^{31}$ The effects of immune-derived stress on the CNS and the periphery, and the subsequent effects on depressed and anxious mood, are not a point of contention in MDD research; ${ }^{32-34}$ however, the exact mechanistic nature of this process and the specific effects of immunological agents are not completely elucidated. In psychiatric disorders, with particular emphasis on depression, there is evidence for a dysregulation of the balance of immunomodulatory cytokines in consequence to an increased preponderance of proinflammatory cytokines (for example, interleukin-1 $\beta$, interleukin- 6 , tumor necrosis factor- $\alpha$ and interferon- $\alpha-\alpha$ ) due to stress. ${ }^{35-38}$ As well, the administration of pro-inflammatory cytokines in both animals ${ }^{39}$ and euthymic subjects ${ }^{40,41}$ triggers the onset of depressive symptomatology, such as depressed mood, fatigue, anhedonia and anorexia. ${ }^{42-44}$ Furthermore, alterations in the proinflammatory/anti-inflammatory cytokine balance has been demonstrated as being an explanatory factor for the way the brain adapts to stress. ${ }^{45}$ The administration of interferon- $\alpha$ has been demonstrated to generate depressivelike symptoms, ${ }^{46,47}$ although its exact mechanism of action 
Table 1 The 32 probesets found to be significantly associated with the change in HAMD score and meeting 0.10 FDR criteria

\begin{tabular}{|c|c|c|c|c|c|c|c|}
\hline Probeset & $\begin{array}{l}\text { Gene } \\
\text { symbol }\end{array}$ & Gene title & Cytoband & $\begin{array}{c}\text { P-value } \\
\text { (uncorrected) }\end{array}$ & FDR & $\begin{array}{l}\text { Fold } \\
\text { change }\end{array}$ & Direction \\
\hline 208436_s_at & IRF7 & Interferon regulatory factor 7 & $11 \mathrm{p} 15.5$ & 0.0002 & 0.0316 & 1.12 & UP \\
\hline 228230_at & PRIC285 & $\begin{array}{l}\text { Peroxisomal proliferator-activated } \\
\text { receptor } A \text { interacting complex } 285\end{array}$ & $20 \mathrm{q} 13.33$ & 0.0021 & 0.0644 & 1.10 & UP \\
\hline 218429_s_at & C19orf66 & Chromosome 19 open reading frame 66 & $19 p 13.2$ & 0.0024 & 0.0653 & 1.11 & UP \\
\hline 209417_s_at & IFI35 & Interferon-induced protein 35 & $17 q 21$ & 0.0025 & 0.0656 & 1.10 & UP \\
\hline 239266_at & - & - & - & 0.0027 & 0.0660 & -1.07 & DOWN \\
\hline 53720_āt & C19orf66 & Chromosome 19 open reading frame 66 & $19 \mathrm{p} 13.2$ & 0.0037 & 0.0676 & 1.11 & UP \\
\hline 203258_at & DRAP1 & $\begin{array}{l}\text { DR1-associated protein } 1 \text { (negative } \\
\text { cofactor } 2 \alpha \text { ) }\end{array}$ & $11 q 13.3$ & 0.004 & 0.0680 & 1.09 & UP \\
\hline 212647_at & $R R A S$ & $\begin{array}{l}\text { Related RAS viral (r-ras) oncogene } \\
\text { homolog }\end{array}$ & 19q13.3-qter & 0.004 & 0.0680 & 1.11 & UP \\
\hline 229803_s_at & - & - & - & 0.0042 & 0.0682 & -1.08 & DOWN \\
\hline 227299_at & CCNI & Cyclin I & $4 q 21.1$ & 0.0044 & 0.0684 & 1.10 & UP \\
\hline 210740_s_at & ITPK1 & Inositol 1,3,4-triphosphate 5/6 kinase & $14 q 31$ & 0.005 & 0.0688 & 1.08 & UP \\
\hline 206284_x_at & CLTB & Clathrin, light chain (Lcb) & $4 q 2-q 315 q 35$ & 0.0054 & 0.0691 & 1.11 & UP \\
\hline 1555491_a_at & C19orf66 & Chromosome 19 open reading frame 66 & $19 \mathrm{p} 13.2$ & 0.0057 & 0.0692 & 1.09 & UP \\
\hline 229350_x_at & PARP10 & $\begin{array}{l}\text { Poly (ADP-ribose) polymerase family, } \\
\text { member } 10\end{array}$ & $8 q 24.3$ & 0.0066 & 0.0735 & 1.08 & UP \\
\hline 215749_s_at & GORASP1 & $\begin{array}{l}\text { Golgi reassembly stacking protein } 1 \text {, } \\
65 \mathrm{kDa}\end{array}$ & 3p22-p21.33 & 0.0078 & 0.0781 & 1.08 & UP \\
\hline 205875_s_at & TREX1 & Three prime repair exonuclease 1 & $3 p 21.31$ & 0.0097 & 0.0838 & 1.10 & UP \\
\hline 1562836_at & - & - & - & 0.0109 & 0.0867 & -1.12 & DOWN \\
\hline 1558937_s_at & - & - & - & 0.0122 & 0.0893 & -1.13 & DOWN \\
\hline 202779_s_at & UBE2S & $\begin{array}{l}\text { Similar to ubiquitin-conjugating } \\
\text { enzyme E2 } \\
\text { Subiquitin-conjugating enzyme E2S }\end{array}$ & $19 q 13.43$ & 0.0128 & 0.0904 & 1.13 & UP \\
\hline 225058_at & GPR108 & G protein-coupled receptor 108 & $19 \mathrm{p} 13.3$ & 0.0132 & 0.0911 & 1.10 & UP \\
\hline 220998_s_at & UNC93B1 & Unc-93 homolog B1 (C. elegans) & $11 \mathrm{q} 13$ & 0.0147 & 0.0933 & 1.09 & UP \\
\hline 235292_at & FLJ32255 & Hypothetical protein LOC643977 & $5 p 12$ & 0.0148 & 0.0935 & 1.10 & UP \\
\hline 202687_s_at & TNFSF10 & $\begin{array}{l}\text { Tumor necrosis factor (ligand) } \\
\text { superfamily, member } 10\end{array}$ & $3 q 26$ & 0.0157 & 0.0947 & 1.13 & UP \\
\hline 207713_s_at & $R B C K 1$ & $\begin{array}{l}\text { RanBP-type and C3HC4-type zinc } \\
\text { finger containing } 1\end{array}$ & $20 p 13$ & 0.0164 & 0.0955 & 1.09 & UP \\
\hline 223152_at & PPP1R12C & $\begin{array}{l}\text { Protein phosphatase 1, regulatory } \\
\text { (inhibitor) subunit } 12 C\end{array}$ & $19 q 13.42$ & 0.0169 & 0.0961 & 1.12 & UP \\
\hline 211250_s_at & SH3BP2 & SH3-domain binding protein 2 & $4 p 16.3$ & 0.0172 & 0.0964 & 1.09 & UP \\
\hline 213621_s_at & GUK1 & Guanylate kinase 1 & $1 q 32-q 41$ & 0.0178 & 0.0971 & 1.15 & UP \\
\hline 218961_s_at & PNKP & Polynucleotide kinase 3'-phosphatase & $19 q 13.3-q 13.4$ & 0.0187 & 0.0980 & 1.08 & UP \\
\hline 212983_at & HRAS & $\begin{array}{l}\text { v-Ha-ras Harvey rat sarcoma viral } \\
\text { oncogene homolog }\end{array}$ & $11 \mathrm{p} 15.5$ & 0.0193 & 0.0985 & 1.12 & UP \\
\hline 222660_s_at & RNF38 & Ring finger protein 38 & $9 p 13$ & 0.0197 & 0.0989 & -1.08 & DOWN \\
\hline 225294_s_at & TRAPPC1 & Trafficking protein particle complex 1 & $17 \mathrm{p} 13.1$ & 0.0202 & 0.0993 & 1.11 & UP \\
\hline 204858 s at & TYMP & Thymidine phosphorylase & $22 \mathrm{q} 13 \mathrm{|} 22 \mathrm{q} 13.33$ & 0.0207 & 0.0997 & 1.13 & UP \\
\hline
\end{tabular}

Abbreviations: DOWN, downregulated; FDR, false discovery rate; HAMD, Hamilton Rating Scale for Depression; UP, upregulated.

Information of differential gene expression between pre- and post-treatment values is represented through a fold change (post/pre) and the directionality of expression following treatment (UP and DOWN).

and pathological consequences still remain predominantly underexplored. ${ }^{48}$

Recently, Spijker et al. ${ }^{49}$ published peripheral gene expression findings following stimulation with lipopolysaccharide, a lipoglycan shown to produce depressive-like behaviors in humans. ${ }^{50}$ In this study, the authors found a difference in stimulated gene expression in MDD versus controls, leading to the identification of a predominantly immune-related biomarker with enough sensitivity and specificity to differentiate between cases and controls.

Traditionally, studies have used peripheral cells, such as lymphocytes or platelets, from affected patients to investigate markers of illness in vitro. These studies have several limitations. For instance, cell models, although informative, do not represent normal cell environment and lack the complexity of the host organism. The investigation of peripheral cells in vivo, rather than in vitro, addresses some of the limitations of previous studies, and as such, a few gene expression studies investigating peripheral samples have been recently conducted in neuropsychiatric conditions such as autism, ${ }^{51-55}$ schizophrenia ${ }^{56,57}$ and Alzheimer's disease. ${ }^{19,20}$ However, one of the central questions of these studies, particularly when they are interested in the investigation of markers of illness, is whether or not their findings are representative of gene changes taking place in the brain. Peripheral studies of drug response, on the other hand, have value not only as a proxy model of CNS phenomena, but as an indicator of peripheral processes involved in individual response to treatment. ${ }^{58-62}$ Examples of peripheral factors involved in drug response include pharmacokinetic, pharmacodynamic, metabolizing and endocrinal factors, all of which may influence peripheral mRNA expression.

That said, it remains important to assess the CNS validity of mRNA expression differences seen in peripheral tissues. 
Table 2 Gene ontology analysis of probesets significantly associated with citalopram response

\begin{tabular}{llrr}
\hline Category & Term & Count & $\%$ \\
\hline Biological process & Nucleobase, nucleoside and nucleotide metabolic process & 4 & P-value \\
Molecular function & Hydrolase activity, acting on acid anhydrides & 5 & $13.33 \%$ \\
Molecular function & Hydrolase activity, acting on acid anhydrides, & $16.67 \%$ & 0.0057 \\
& in phosphorus-containing anhydrides & 5 & $16.67 \%$ \\
Molecular function & Pyrophosphatase activity & 5 & 16.0109 \\
Molecular function & Nuclease activity & 3 & 0.0133 \\
Cellular component & Golgi apparatus & 4 & $10.00 \%$ \\
Molecular function & Ribonucleotide binding & 7 & $13.33 \%$ \\
Cellular component & Golgi apparatus & 4 & $23.33 \%$ \\
Molecular function & Purine nucleotide binding & 7 & 0.0146 \\
Biological process & Nucleotide metabolic process & 3 & 0.0278 \\
Molecular function & Purine ribonucleotide binding & 7 & 0.0341 \\
Biological process & DNA replication & $3.33 \%$ \\
\hline
\end{tabular}

Count refers to the number of probesets (out of 32) that belong to the ontological category and term, the percentage (\%) to which this corresponds and the $P$-value of the association.

Table 3 Validation of microarray findings using GeXP or qPCR

\begin{tabular}{|c|c|c|c|c|c|c|c|}
\hline \multirow[t]{2}{*}{ Gene } & \multirow[t]{2}{*}{ Probeset } & \multirow{2}{*}{$\begin{array}{c}\text { Uncorrected } \\
\text { P-value } \\
\text { Microarray }\end{array}$} & \multirow[t]{2}{*}{$F D R$} & \multirow{2}{*}{$\begin{array}{c}\text { Fold change } \\
\text { (pre/post) }\end{array}$} & \multirow{2}{*}{$\begin{array}{c}\text { Fold change } \\
\text { (pre/post) } \\
\text { GeXP or real time }\end{array}$} & \multicolumn{2}{|c|}{ Pearson's correlation } \\
\hline & & & & & & $r$ & P-value \\
\hline IRF7 & 208436_s_at & 0.0002 & 0.032 & 1.12 & 1.09 & 0.631 & $<0.0001$ \\
\hline PRIC285 & 228230_at & 0.002 & 0.064 & 1.10 & 1.15 & -0.115 & 0.234 \\
\hline C19orf66 & 218429_s_at & 0.002 & 0.065 & 1.11 & 1.17 & 0.286 & 0.003 \\
\hline IFI35 & 209417_s_at & 0.003 & 0.066 & 1.10 & 1.03 & 0.477 & $<0.0001$ \\
\hline C19orf66 & 53720_at & 0.004 & 0.068 & 1.11 & 1.17 & 0.248 & 0.01 \\
\hline CCN1 & 227299_at & 0.004 & 0.068 & 1.10 & 1.06 & -0.063 & 0.255 \\
\hline$D R A P 1$ & 203258_at & 0.004 & 0.068 & 1.09 & 1.06 & 0.141 & 0.066 \\
\hline$C L T B$ & 206284_x_at & 0.005 & 0.069 & 1.11 & 1.02 & 0.009 & 0.461 \\
\hline ITPK1 & 210740_s_at & 0.005 & 0.069 & 1.08 & 1.06 & 0.036 & 0.352 \\
\hline C19orf66 & 1555491_a_at & 0.006 & 0.069 & 1.09 & 1.17 & 0.265 & 0.006 \\
\hline TREX1 & 205875_s_at & 0.009 & 0.084 & 1.10 & 1.09 & 0.281 & 0.001 \\
\hline GPR108 & 225058_at & 0.013 & 0.091 & 1.10 & 1.02 & -0.076 & 0.208 \\
\hline FLJ32255 & 235292_at & 0.015 & 0.093 & 1.10 & 1.00 & 0.085 & 0.184 \\
\hline UNC93B1 & 220998_s_at & 0.015 & 0.093 & 1.09 & 1.10 & 0.157 & 0.046 \\
\hline TNFSF10 & 202687_s_at & 0.016 & 0.095 & 1.13 & 1.03 & 0.056 & 0.276 \\
\hline PPP1R12C & 223152_at & 0.017 & 0.096 & 1.12 & 1.02 & -0.017 & 0.428 \\
\hline SH3BP2 & 211250_s_at & 0.017 & 0.096 & 1.09 & 1.01 & -0.015 & 0.438 \\
\hline GUK1 & 213621_s_at & 0.018 & 0.097 & 1.15 & 1.12 & 0.332 & $<0.0001$ \\
\hline HRAS & 212983_at & 0.019 & 0.099 & 1.12 & 1.07 & 0.072 & 0.225 \\
\hline RNF38 & 222660_s_at & 0.019 & 0.099 & -1.08 & 1.01 & 0.116 & 0.108 \\
\hline TRAPPC1 & 225294_s_at & 0.02 & 0.099 & 1.11 & 1.03 & -0.101 & 0.141 \\
\hline
\end{tabular}

Abbreviations: CCN1, cyclin 1; CLTB, clathrin, light chain (Lcb); C19orf66, chromosome 19 open reading frame 66; DRAP1, DR1-associated protein 1 (negative cofactor $2 \alpha$ ); FDR, false discovery rate; FLJ32255, hypothetical protein LOC643977; GUK1, guanylate kinase 1; GPR108, G protein-coupled receptor 108; HRAS, $v$-Ha-ras Harvey rat sarcoma viral oncogene homolog; IFI35, interferon-induced protein 35; IRF7, interferon regulatory factor 7; ITPK1, inositol 1,3,4-triphosphate 5/6 kinase; PARP10, poly (ADP-ribose) polymerase family, member 10; PPP1R12C, protein phosphatase 1, regulatory (inhibitor) subunit 12C; PRIC285, peroxisomal proliferator-activated receptor A interacting complex 285; RNF38, ring finger protein 38; SH3BP2, SH3-domain binding protein 2; TNFSF10, tumor necrosis factor (ligand) superfamily, member 10; TRAPPC1, trafficking protein particle complex 1; TREX1, three prime repair exonuclease 1; UNC93B1, Unc-93 homolog B1 (C. elegans).

The first three columns contain data from the microarray, whereas the fourth column presents fold change results from quantitative validation and the last two columns give Pearson's correlation $(r)$ and $P$-value of the correlation between the microarray results and quantitative validation.

When investigating the pattern of prefrontal cortex gene expression of IRF7, we found its expression to be significantly downregulated in MDD compared with controls in frontal cortex. A limitation of post-mortem investigations is that information on antidepressant medication history of individual subjects is restricted. However, availability of toxicological data partially reduces the impact of this limitation. Although our post-mortem results do not represent by themselves a validation of our peripheral findings, they certainly support the hypothesis that IRF7 may play a role in brain processes associated with depression. We are limited in our design by the lack of a placebo or control group for comparison. However, it must be said that the aim of the present study was to determine biomarkers of response and not to perform an assessment of drug efficacy. Although assessing molecular processes associated with placebo effects is also a relevant question, withholding potentially beneficial treatment from actively depressed individuals is nowadays considered unethical in many countries, including the one where this study was conducted. It was nevertheless reassuring that we observed similarities with other studies having used citalopram regarding noticeable side effects during the course of treatment ${ }^{63}$ and in the range of citalopram concentrations quantified in plasma. ${ }^{64-67}$ In all, our findings do provide good indications of plausible treatment targets and likely biomarkers for depression and citalopram response. 


\section{Conflict of interest}

The authors declare no conflict of interest.

Acknowledgements. All authors had full access to all of the data in the study and take responsibility for the integrity of the data and the accuracy of the data analysis. We thank Richard Violette for his help in the collection of information pertaining to the post-mortem sample.

1. Murray CJL, Lopez AD. The Global Burden of Disease. WHO: Geneva, 1998.

2. Bauer M, Whybrow PC, Angst J, Versiani M, Moller HJ. World Federation of Societies o Biological Psychiatry (WFSBP) Guidelines for Biological Treatment of Unipolar Depressive Disorders, Part 1: acute and continuation treatment of major depressive disorder. World $J$ Biol Psychiatry 2002; 3: 5-43.

3. Evans WE, Johnson JA. Pharmacogenomics: the inherited basis for interindividual differences in drug response. Annu Rev Genomics Hum Genet 2001; 2: 9-39.

4. McLeod HL, Evans WE. Pharmacogenomics: unlocking the human genome for better drug therapy. Annu Rev Pharmacol Toxicol 2001; 41: 101-121.

5. Nelson JC. Managing treatment-resistant major depression. J Clin Psychiatry 2003; 64(Suppl 1): 5-12.

6. Trivedi MH, Rush AJ, Wisniewski SR, Nierenberg AA, Warden D, Ritz L et al. Evaluation of outcomes with citalopram for depression using measurement-based care in $S T A R^{*} D$ : implications for clinical practice. Am J Psychiatry 2006; 163: 28-40.

7. Kemp AH, Gordon E, Rush AJ, Williams LM. Improving the prediction of treatment response in depression: integration of clinical, cognitive, psychophysiological, neuroimaging, and genetic measures. CNS Spectr 2008; 13: 1066-1086.

8. Akiskal HS, Bourgeois ML, Angst J, Post R, Moller H, Hirschfeld R. Re-evaluating the prevalence of and diagnostic composition within the broad clinical spectrum of bipolar disorders. J Affect Disord 2000; 59(Suppl 1): S5-S30.

9. Franchini L, Serretti A, Gasperini M, Smeraldi E. Familial concordance of fluvoxamine response as a tool for differentiating mood disorder pedigrees. J Psychiatr Res 1998; 32 255-259.

10. Serretti A, Franchini L, Gasperini M, Rampoldi R, Smeraldi E. Mode of inheritance in mood disorder families according to fluvoxamine response. Acta Psychiatr Scand 1998; 98: 443-450.

11. Chang JC, Wooten EC, Tsimelzon A, Hilsenbeck SG, Gutierrez MC, Elledge R et al. Gene expression profiling for the prediction of therapeutic response to docetaxel in patients with breast cancer. Lancet 2003; 362: 362-369.

12. Nagasaki K, Miki Y. Molecular prediction of the therapeutic response to neoadjuvant chemotherapy in breast cancer. Breast Cancer 2008; 15: 117-120.

13. Zembutsu H, Suzuki Y, Sasaki A, Tsunoda T, Okazaki M, Yoshimoto M et al. Predicting response to docetaxel neoadjuvant chemotherapy for advanced breast cancers through genome-wide gene expression profiling. Int J Oncol 2009; 34: 361-370

14. Schetter AJ, Leung SY, Sohn JJ, Zanetti KA, Bowman ED, Yanaihara N et al. MicroRNA expression profiles associated with prognosis and therapeutic outcome in colon adenocarcinoma. JAMA 2008; 299: 425-436.

15. Kittleson MM, Minhas KM, Irizarry RA, Ye SQ, Edness G, Breton E et al. Gene expression in giant cell myocarditis: altered expression of immune response genes. Int J Cardiol 2005 102: 333-340.

16. Marziliano N, Grasso M, Pilotto A, Porcu E, Tagliani M, Disabella E et al. Transcriptomic and proteomic analysis in the cardiovascular setting: unravelling the disease? J Cardiovasc Med (Hagerstown) 2009; 10: 433-442.

17. Matkovich SJ, Van Booven DJ, Youker KA, Torre-Amione G, Diwan A, Eschenbacher WH et al. Reciprocal regulation of myocardial microRNAs and messenger RNA in human cardiomyopathy and reversal of the microRNA signature by biomechanical support. Circulation 2009; 119: 1263-1271.

18. Kalman J, Palotas A, Juhasz A, Rimanoczy A, Hugyecz M, Kovacs Z et al. Impact of venlafaxine on gene expression profile in lymphocytes of the elderly with majo depression-evolution of antidepressants and the role of the "neuro-immune" system. Neurochem Res 2005; 30: 1429-1438.

19. Palotas A, Puskas LG, Kitajka K, Palotas M, Molnar J, Pakaski M et al. Altered response to mirtazapine on gene expression profile of lymphocytes from Alzheimer's patients. Eur $J$ Pharmacol 2004; 497: 247-254.

20. Palotas A, Puskas LG, Kitajka K, Palotas M, Molnar J, Pakaski M et al. The effect of citalopram on gene expression profile of Alzheimer lymphocytes. Neurochem Res 2004 29: 1563-1570.

21. Belzeaux R, Formisano-Treziny C, Loundou A, Boyer L, Gabert J, Samuelian JC et al. Clinical variations modulate patterns of gene expression and define blood biomarkers in major depression. J Psychiatr Res 2010; 44: 1205-1213.

22. Iga J, Ueno S, Yamauchi K, Numata S, Kinouchi S, Tayoshi-Shibuya S et al. Altered HDAC5 and CREB mRNA expressions in the peripheral leukocytes of major depression. Prog Neuropsychopharmacol Biol Psychiatry 2007; 31: 628-632.

23. Iga J, Ueno S, Yamauchi K, Numata S, Tayoshi-Shibuya S, Kinouchi S et al. Gene expression and association analysis of vascular endothelial growth factor in majo depressive disorder. Prog Neuropsychopharmacol Biol Psychiatry 2007; 31: 658-663.
24. McClintick JN, Edenberg HJ. Effects of filtering by present call on analysis of microarray experiments. BMC Bioinformatics 2006; 7: 49.

25. Streiner DL. Breaking up is hard to do: the heartbreak of dichotomizing continuous data. Can J Psychiatry 2002; 47: 262-266.

26. Huang dW, Sherman BT, Lempicki RA. Systematic and integrative analysis of large gene lists using DAVID bioinformatics resources. Nat Protoc 2009; 4: 44-57.

27. Hercher C, Turecki G, Mechawar N. Through the looking glass: examining neuroanatomical evidence for cellular alterations in major depression. J Psychiatr Res 2009; 43: 947-961.

28. Paun A, Pitha PM. The IRF family, revisited. Biochimie 2007; 89: 744-753.

29. Honda K, Yanai H, Negishi H, Asagiri M, Sato M, Mizutani T et al. IRF-7 is the master regulator of type-l interferon-dependent immune responses. Nature 2005; 434: 772-777.

30. Lu R, Au WC, Yeow WS, Hageman N, Pitha PM. Regulation of the promoter activity of interferon regulatory factor-7 gene. Activation by interferon snd silencing by hypermethylation. J Biol Chem 2000; 275: 31805-31812.

31. Anisman $\mathrm{H}$, Merali $\mathrm{Z}$. Anhedonic and anxiogenic effects of cytokine exposure. Adv Exp Med Biol 1999; 461: 199-233.

32. Dantzer R, O'Connor JC, Freund GG, Johnson RW, Kelley KW. From inflammation to sickness and depression: when the immune system subjugates the brain. Nat Rev Neurosci 2008. 9: 46-56.

33. Maes M. Evidence for an immune response in major depression: a review and hypothesis. Prog Neuropsychopharmacol Biol Psychiatry 1995; 19: 11-38

34. Maes M. Major depression and activation of the inflammatory response system. Adv Exp Med Biol 1999; 461: 25-46.

35. Kim YK, Na KS, Shin KH, Jung HY, Choi SH, Kim JB. Cytokine imbalance in the pathophysiology of major depressive disorder. Prog Neuropsychopharmacol Biol Psychiatry 2007; 31: 1044-1053.

36. Maes M, Song C, Lin A, De JR, Van GA, Kenis $G$ et al. The effects of psychological stress on humans: increased production of pro-inflammatory cytokines and a Th1-like response in stress-induced anxiety. Cytokine 1998; 10: 313-318.

37. Qin L, Wu X, Block ML, Liu Y, Breese GR, Hong JS et al. Systemic LPS causes chronic neuroinflammation and progressive neurodegeneration. Glia 2007; 55: 453-462.

38. Seidel A, Arolt V, Hunstiger M, Rink L, Behnisch A, Kirchner H. Increased CD56+ natural killer cells and related cytokines in major depression. Clin Immunol Immunopathol 1996; 78: 83-85.

39. Kent S, Bluthe RM, Kelley KW, Dantzer R. Sickness behavior as a new target for drug development. Trends Pharmacol Sci 1992; 13: 24-28.

40. Capuron L, Ravaud A. Prediction of the depressive effects of interferon alfa therapy by the patient's initial affective state. N Engl J Med 1999; 340: 1370.

41. McDonald EM, Mann AH, Thomas HC. Interferons as mediators of psychiatric morbidity. An investigation in a trial of recombinant alpha-interferon in hepatitis-B carriers. Lancet 1987; 2: 1175-1178.

42. Maes M, Meltzer HY, Scharpe S, Cooreman W, Uyttenbroeck W, Suy E et al. Psychomotor retardation, anorexia, weight loss, sleep disturbances, and loss of energy: psychopathological correlates of hyperhaptoglobinemia during major depression. Psychiatry Res 1993; 47: 229-241.

43. Schiepers OJ, Wichers MC, Maes M. Cytokines and major depression. Prog Neuropsychopharmacol Biol Psychiatry 2005; 29: 201-217.

44. Yirmiya R, Weidenfeld J, Pollak Y, Morag M, Morag A, Avitsur R et al. Cytokines, "depression due to a general medical condition," and antidepressant drugs. Adv Exp Med Biol 1999; 461: 283-316.

45. Anisman H, Merali Z. Cytokines, stress and depressive illness: brain-immune interactions. Ann Med 2003; 35: 2-11.

46. Cassidy EM, Manning D, Byrne S, Bolger E, Murray F, Sharifi N et al. Acute effects of lowdose interferon-alpha on serum cortisol and plasma interleukin-6. J Psychopharmacol 2002; 16: 230-234

47. Shimizu H, Ohtani K, Sato N, Nagamine T, Mori M. Increase in serum interleukin-6, plasma ACTH and serum cortisol levels after systemic interferon-alpha administration. Endocr $J$ 1995; 42: 551-556.

48. Anisman $\mathrm{H}$. Cascading effects of stressors and inflammatory immune system activation: implications for major depressive disorder. J Psychiatry Neurosci 2009; 34: 4-20.

49. Spijker S, Van Zanten JS, De JS, Penninx BW, van DR, Zitman FG et al. Stimulated gene expression profiles as a blood marker of major depressive disorder. Biol Psychiatry 2010; 68: $179-186$

50. Reichenberg A, Yirmiya R, Schuld A, Kraus T, Haack M, Morag A et al. Cytokineassociated emotional and cognitive disturbances in humans. Arch Gen Psychiatry 2001; 58: $445-452$.

51. Hu VW, Frank BC, Heine S, Lee NH, Quackenbush J. Gene expression profiling of lymphoblastoid cell lines from monozygotic twins discordant in severity of autism reveals differential regulation of neurologically relevant genes. BMC Genomics 2006; 7: 118.

52. Hu VW, Nguyen A, Kim KS, Steinberg ME, Sarachana T, Scully MA et al. Gene expression profiling of lymphoblasts from autistic and nonaffected sib pairs: altered pathways in neuronal development and steroid biosynthesis. PLoS One 2009; 4: e5775.

53. Hu VW, Sarachana T, Kim KS, Nguyen A, Kulkarni S, Steinberg ME et al. Gene expression profiling differentiates autism case-controls and phenotypic variants of autism spectrum disorders: evidence for circadian rhythm dysfunction in severe autism. Autism Res 2009; 2 78-97. 
54. Nishimura Y, Martin CL, Vazquez-Lopez A, Spence SJ, Alvarez-Retuerto Al, Sigman M et al. Genome-wide expression profiling of lymphoblastoid cell lines distinguishes different forms of autism and reveals shared pathways. Hum Mol Genet 2007; 16: 1682-1698.

55. Talebizadeh Z, Butler MG, Theodoro MF. Feasibility and relevance of examining lymphoblastoid cell lines to study role of microRNAs in autism. Autism Res 2008; 1 : 240-250.

56. Chagnon YC, Roy MA, Bureau A, Merette C, Maziade M. Differential RNA expression between schizophrenic patients and controls of the dystrobrevin binding protein 1 and neuregulin 1 genes in immortalized lymphocytes. Schizophr Res 2008; 100: 281-290.

57. Suzuki K, Nakamura K, Iwata Y, Sekine Y, Kawai M, Sugihara G et al. Decreased expression of reelin receptor VLDLR in peripheral lymphocytes of drug-naive schizophrenic patients. Schizophr Res 2008; 98: 148-156.

58. de LJ, Susce MT, Johnson M, Hardin M, Maw L, Shao A et al. DNA microarray technology in the clinical environment: the AmpliChip CYP450 test for CYP2D6 and CYP2C19 genotyping. CNS Spectr 2009; 14: 19-34.

59. Domenici E, Wille DR, Tozzi F, Prokopenko I, Miller S, McKeown A et al. Plasma protein biomarkers for depression and schizophrenia by multi analyte profiling of case-control collections. PLoS One 2010; 5: e9166.

60. Fisar Z, Kalisova L, Paclt I, Anders M, Vevera J. Platelet serotonin uptake in drug-naive depressive patients before and after treatment with citalopram. Psychiatry Res 2008; 161: 185-194.

61. Miller WR, Larionov A, Renshaw L, Anderson TJ, Walker JR, Krause A et al. Gene expression profiles differentiating between breast cancers clinically responsive or resistant to letrozole. J Clin Oncol 2009; 27: 1382-1387.
62. Swen JJ, Huizinga TW, Gelderblom $\mathrm{H}$, de Vries EG, Assendelft WJ, Kirchheiner J et al. Translating pharmacogenomics: challenges on the road to the clinic. PLOS Med 2007; 4 e209.

63. Uher R, Farmer A, Henigsberg N, Rietschel M, Mors O, Maier W et al. Adverse reactions to antidepressants. Br J Psychiatry 2009; 195: 202-210.

64. Baumann P, Rochat B. Comparative pharmacokinetics of selective serotonin reuptake inhibitors: a look behind the mirror. Int Clin Psychopharmacol 1995; 10(Suppl 1): 15-21.

65. Bezchlibnyk-Butler K, Aleksic I, Kennedy SH. Citalopram-a review of pharmacological and clinical effects. J Psychiatry Neurosci 2000; 25: 241-254.

66. Bjerkenstedt L, Flyckt L, Overo KF, Lingjaerde O. Relationship between clinical effects, serum drug concentration and serotonin uptake inhibition in depressed patients treated with citalopram. A double-blind comparison of three dose levels. Eur J Clin Pharmacol 1985; 28: 553-557.

67. Leinonen $\mathrm{E}$, Lepola $\mathrm{U}$, Koponen $\mathrm{H}$, Kinnunen I. The effect of age and concomitant treatment with other psychoactive drugs on serum concentrations of citalopram measured with a nonenantioselective method. Ther Drug Monit 1996; 18: 111-117.

Translational Psychiatry is an open-access journal published by Nature Publishing Group. This work is licensed under the Creative Commons Attribution-Noncommercial-No Derivative Works 3.0 Unported License. To view a copy of this license, visit http://creativecommons.org/licenses/by-nc-nd/3.0/

\section{Supplementary Information accompanies the paper on the Translational Psychiatry website (http://www.nature.com/tp)}

